\title{
Effects of forebrain serotonin depletion on fenfluramine-induced taste aversions
}

\author{
JOAN F. LORDEN, MICHAEL CALLAHAN, and RALPH DAWSON, JR. \\ University of Alabama in Birmingham, Birmingham, Alabama 35294
}

\begin{abstract}
Both nonspecific electrolytic and chemically specific 5,7-dihydroxytryptamine lesions of the median and dorsal raphe nuclei of the rat potentiated the suppressive effects of pairing a single injection of fenfluramine $\mathrm{HCl}$ with the ingestion of a novel fluid. No general alterations in fluid intake were observed as a result of the lesion. Nor did the lesions cause any significant changes in body weight. Telencephalic serotonin content was reduced by $53 \%-57 \%$ in the lesion groups. The study suggests that although fenfluramine may act on serotonergic systems, the drug's effectiveness in the conditioned aversion paradigm does not depend on the integrity of the ascending serotonergic projections of the raphe. The results described here are comparable to those reported previously when lithium chloride rather than fenfluramine was used to induce an aversion in serotonin-depleted rats.
\end{abstract}

Depletion of forebrain serotonin (5-HT) is associated with increases in sensitivity to painful cutaneous stimuli (Harvey \& Lints, 1971; Koe \& Weissman, 1966; Tenen, 1967). In active avoidance paradigms that use footshock as an unconditioned stimulus, facilitation of performance is observed (Lorens, 1973; Lorens, Sorenson, \& Yunger, 1971; Lorens \& Yunger, 1974; Srebro \& Lorens, 1975). Recently, it has also been shown that reduction of forebrain 5-HT enhances learned aversions to taste cues (Lorden \& Margules, 1977).

The conditioned taste aversion is a passive avoidance response in which ingestion of a novel-tasting fluid is paired with a drug injection. Gastrointestinal distress or other drug effects are presumed to serve as unconditioned stimuli. The suppression of intake of a novel fluid that has been paired with a single drug injection is increased in rats with electrolytic or 5,7-dihydroxytryptamine (5,7-DHT) lesions of the midbrain raphe nuclei that deplete 5-HT (Lorden \& Margules, 1977). Suppression is blocked or attenuated in serotonin-depleted and normal rats treated immediately prior to the conditioning trial with the 5-HT precursor, 5-hydroxytryptophan (Lorden \& Oltmans, 1978). These experiments suggest that changes in central serotonergic neurons may modify the acquisition of a conditioned taste aversion.

Previous investigations of the effects of manipulation of 5-HT levels on taste aversion learning have used lithium chloride ( $\mathrm{LiCl})$ as the agent paired with fluid ingestion (Lorden \& Margules, 1977; Lorden \& Oltmans, 1978). In the conditioned aversion paradigm, $\mathrm{LiCl}$ is presumed to act peripherally to produce

This research was supported in part by NIMH Grant MH30389-01, NSF Grant BNS 77-15251, and a UAB Faculty Research Grant. The fenfluramine was a gift of the A. H. Robins Co. some form of gastrointestinal distress which is associated with the novel flavor (Nachman, 1963, 1970). In recent years, however, many drugs have been shown to be effective in producing taste aversions, although not all effective drugs produce an obvious malaise (Nachman \& Hartley, 1975). For example, a variety of psychotropic drugs including amphetamine, lorazepam, morphine, and chlordiazepoxide have been shown to induce conditioned taste aversions (Berger, 1972; Cappell, LeBlanc, \& Herling, 1975; Parker, Failor \& Weidman, 1973). At least some of the drugs in this group are effective in producing taste aversions at doses which animals will self-administer (Berger, 1972; Cappell \& LeBlanc, 1971; Carey, 1976; Goudie \& Thornton, 1975). Thus, their effectiveness may depend on central rather than peripheral events.

One approach to the question of the mechanism by which psychoactive drugs produce conditioned taste aversions has been to use brain lesions to block the acquisition of an aversion. For example, intraventricular infusions of 6-hydroxydopamine, the catecholamine neurotoxin, have been shown to block the formation of aversions to saccharin if amphetamine, but not $\mathrm{LiCl}$, is paired with saccharin drinking (Roberts \& Fibiger, 1975). Thus, depletion of central catecholamines interferes with conditioned aversion learning but does so without causing a general learning deficit. This suggests that the effect of amphetamine in the conditioned aversion paradigm depends on its action on central catecholaminergic neurons.

Data from several studies suggest that the compound fenfluramine acts on 5-HT-containing neurons (Clineschmidt, Totaro, McGuffin, Jr., \& Pfleuger, 1976; Harvey \& McMaster, 1975; Quock \& Beal, 1976; Samanin, Ghezzi, Valzelli, \& Garattini, 1972; Trulson \& Jacobs, 1976). However, lesion 
studies which have been conducted to determine whether 5-HT neurons are the site of fenfluramine's action as an appetite suppressant have yielded conflicting results (Hollister, Ervin, Cooper, \& Breese, 1975; Samanin et al., 1972; Sugrue, Goodlet, \& McIndewar, 1975). The mechanism by which fenfluramine acts to produce a conditioned taste aversion is unknown. Thus, several outcomes can be predicted for the use of fenfluramine in the conditioned aversion paradigm in serotonin-depleted rats. The effectiveness of fenfluramine in this paradigm might be blocked by serotonin depletion. Alternatively, fenfluramine may act by a nonserotonergic route to produce a taste aversion. In the latter case, the enhancement of conditioned aversion learning observed when $\mathrm{LiCl}$ is paired with a novel flavor in serotonin-depleted rats might be observed. The experiment reported here examined these possibilities.

\section{METHOD}

\author{
Subjects \\ Male albino rats (Holtzman Co.), weighing 300-350 $\mathrm{g}$ at the time \\ of surgery, were housed in individual cages in a light- and \\ temperature-controlled colony room. A 12-h light-dark cycle was in \\ effect throughout the experiment. Wayne Laboratory Chow and \\ water were available ad lib, unless otherwise noted.
}

\section{Surgery}

An electrolytic lesion group $(\mathrm{N}=8)$ received stereotaxically placed lesions in the dorsal and median raphe nuclei. The electrodes used were epoxy-coated, size 000 insect pins with .5 - $\mathrm{mm}$ exposed tips. The coordinates were: $1 \mathrm{~mm}$ anterior to lambda (AP), $1.2 \mathrm{~mm}$ lateral to the midline (L), and $6.7 \mathrm{~mm}$ ventral $(\mathrm{V})$ to the surface of the skull for the dorsal raphe lesion, and 1.0 (AP), $1.5(\mathrm{~L})$, and 8.6 (V) for the median raphe lesion. The electrode was held at a $10^{\circ}$ angle to the sagittal plane, and the incisor bar was placed $3.5 \mathrm{~mm}$ above the interaural line. The lesions were produced with a $2-\mathrm{mA}$ cathodal current. The current duration was $20 \mathrm{sec}$ for the dorsal lesion and $25 \mathrm{sec}$ for the median lesion.

Two additional groups of rats $(\mathrm{N}=8$ for each) received intracerebral infusions of 5,7-dihydroxytryptamine creatinine sulfate (Regis Chemical Co.) at the same coordinates used for the electrolytic lesions. Animals received either 4 or $6 \mu \mathrm{g}$ (free base) dissolved in $1 \mu \mathrm{l}$ of $.9 \%$ saline containing $.02 \%$ ascorbic acid. The infusion was made through a 30-ga stainless steel cannula attached to a microsyringe. The infusion rate was $.25 \mu \mathrm{l} / \mathrm{min}$.

Two control groups were used. One group $(\mathrm{N}=3)$ received an injection of $1 \mu \mathrm{l}$ of the infusion vehicle at the same coordinates used for the lesions. A second sham-operated group $(N=4)$ received all surgical procedures except that neither an electrode nor a cannula was lowered into the brain. All surgical procedures were performed using ether as the anesthetic.

\section{Behavioral Training and Testing}

Following a 1-month recovery period, all animals were placed on a 23-h water-deprivation schedule. Water was presented in inverted $50-\mathrm{ml}$ centrifuge tubes, fitted with spouts and stoppers. Drinking was measured after $10 \mathrm{~min}$. The centrifuge tubes were then replaced with standard water bottles which remained on the cages for $50 \mathrm{~min}$. Water intake stabilized within a week. On the drug treatment day, all animals were presented with $50 \mathrm{ml}$ of $.1 \%$ saccharin during the 10 -min drinking period. Immediately following the initial $10-$ min drinking period, all animals received an IP drug injection of DL-fenfluramine $\mathrm{HCl}$ (A. H. Robins, $9 \mathrm{mg} / \mathrm{kg}$, dissolved at a concentration of $4.5 \mathrm{mg} / \mathrm{ml}$ ). The drug injections were followed by the usual 50 -min drinking period during which tap water was available. The animals were tested for taste aversions on every other day, starting on the 3rd day after drug treatment. On test days, $50 \mathrm{ml}$ of a $.1 \%$ saccharin solution was presented during the 10-min drinking period. On all intervening days, water was available during both the 10 - and the 50 -min drinking periods.

\section{Chemical Analyses}

Following the completion of the behavioral testing sequence, all rats were sacrificed by decapitation. The brains were rapidly removed and a telencephalic section was dissected (Lorden \& Margules, 1977). The telencephalon was frozen immediately in liquid nitrogen and weighed. At a later date, the sections were assayed fluorometrically for 5-HT by a modification of the method of Hogan, as described by Jacobowitz and Richardson (1978).

\section{Histology}

The brainstems from all animals in the lesion groups were placed in $10 \%$ neutral buffered Formalin at the time of sacrifice. Celloidin-embedded sections were cut at $40 \mu$ and stained with cresyl violet. Lesions and cannula tracks were evaluated microscopically for accuracy of placement.

\section{Data Analysis}

In general, data were analyzed by analysis of variance followed by Newman-Keuls tests. Some comparisons were made using $t$ tests for dependent means, as noted below. Unless otherwise specified, the .05 level of significance was used.

\section{RESULTS}

\section{Histology}

Lesions or cannula placements located in the median and dorsal raphe nuclei were verified in five rats in the electrolytic group and seven animals in each of the 5,7-DHT groups. The data presented below were obtained from these animals. Representative lesion and cannula placements are shown in Figure 1.

\section{Behavior}

No significant differences in the behavior of the vehicle and sham groups were observed. Therefore, the data from these two groups were combined to simplify presentation. The combined groups are referred to as the control group.

Body weight did not differ significantly between groups at the time of training. Mean body weights $(g \pm S D)$ for each group on the day of the training trial were: $5,7-\mathrm{DHT}(4 \mu \mathrm{g}), 415 \pm 45 ; 5,7-\mathrm{DHT}(6 \mu \mathrm{g})$, $415 \pm 25$; electrolytic, $451 \pm 41$; and control, $434 \pm 29$.

Prior to the pairing of saccharin and fenfluramine, there were no significant differences between groups in either saccharin or water consumption (Figure 2). On the first postinjection saccharin presentation, saccharin consumption was reduced significantly, in all groups; however, there were no significant differences between groups on this trial or on the second postinjection saccharin trial. On Days 3 and 4, differences between the groups emerged as the suppression of saccharin consumption dissipated more 


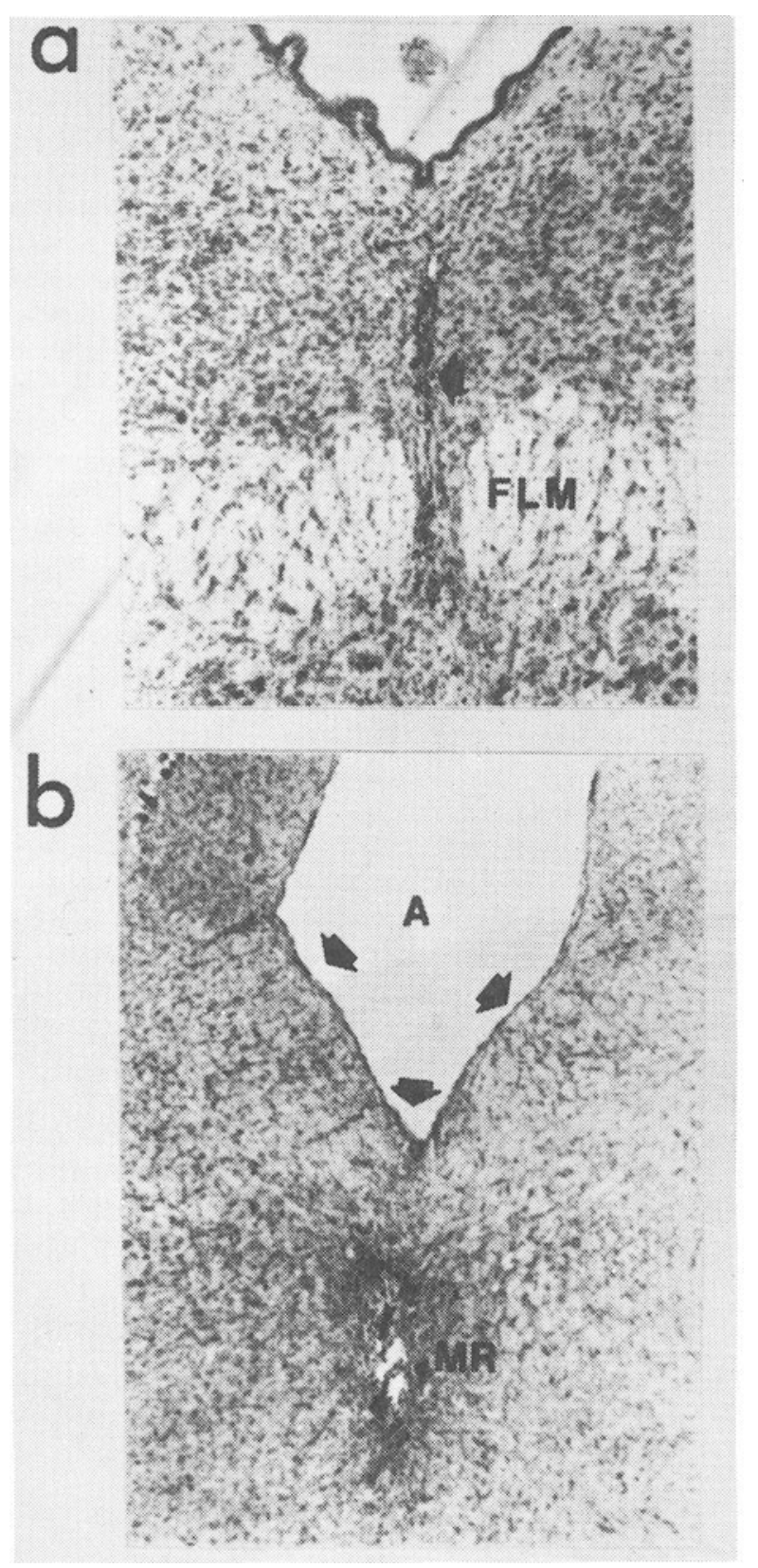

Figure 1 (A) The arrow indicates a cannula track for a rat in the in 6- $\mu \mathrm{g}$ 5,7-DHT group. The cannula is placed in the dorsal raphe nucleus $(40 \times)$. (B) The relatively selective 5,7-DHT lesion (A) can be compared with the large electrolytic lesion which damaged the wall of the aqueduct (arrows) in addition to destroying the dorsal raphe. Damage to the median raphe (MR) is also visible $(20 \times)$. Abbreviations: A, aqueduct; FLM, medial longitudinal fasciculus; $M R$, median raphe nucleus.

rapidly in the control group than in the lesion groups. On Trial 3, both the 5,7-DHT $(6 \mu \mathrm{g})$ group and the electrolytic. group differed significantly from the control group. On Trial 4, all three lesion groups drank significantly less saccharin than the control group. The lesion groups did not differ significantly from each other.
No significant differences in water intake during the 10-min tests were observed between groups at any point in the experiment. On the first day following the training trial, water intake was depressed in all groups. However, $t$ tests for dependent means performed for each group to compare preinjection water intake and the second postinjection water trial yielded nonsignificant results. Thus, there is no evidence that any hypodipsic effects of the drug injection persisted long enough to interfere with the saccharin test trials.

Analysis of water intake during the 50-min drinking period that followed all 10-min tests did not reveal any significant differences between groups (Table 1). All animals decreased their intake markedly after the fenfluramine injection on the training day. Withingroup comparisons indicated that water intake was greater in all groups following saccharin presentations than following water presentations.

\section{Chemical Analysis}

The results of the fluorometric assays of telencephalic 5-HT are presented in Table 2 . The vehicle infusion caused a $21 \%$ decrement in 5-HT. Depletion was greatest $(57 \%)$ in the 5,7-DHT $(6 \mu \mathrm{g})$ group; however, there were no statistically significant differences between lesion groups. All lesion groups differed significantly from the vehicle and sham control groups.

\section{DISCUSSION}

Both chemical and electrolytic lesions of the median and dorsal raphe nuclei have been shown to potentiate

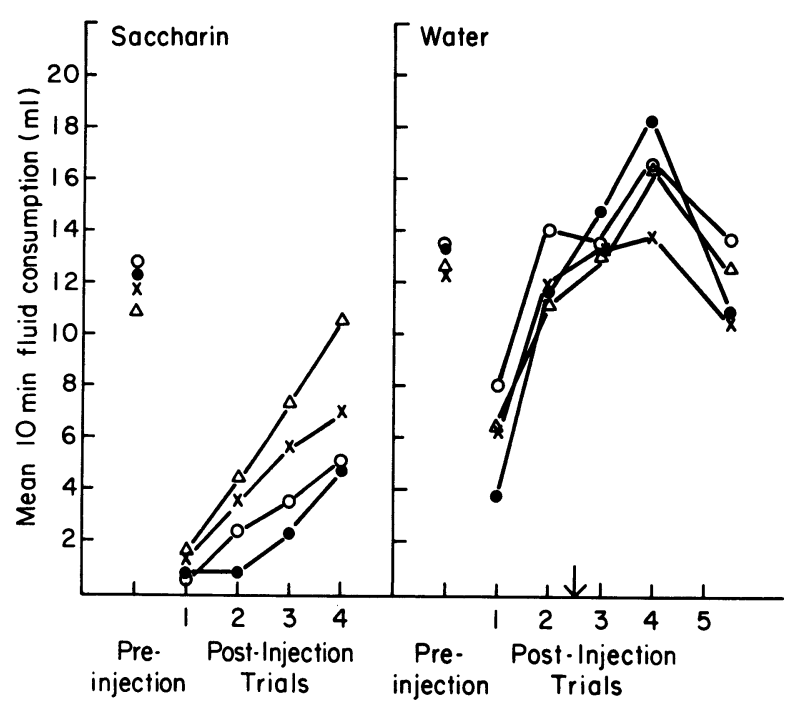

Figure 2. The saccharin (left panel) and water (right) consumption of all groups during the 10 -min test trials immediately prior to and following the pairing of saccharin and fenfluramine. Groups are designated as follows: $\bullet-\bullet, 5,7-D H T(6 \mu \mathrm{g})$; $\times \longrightarrow \times, 5,7-D H T(4 \mu \mathrm{g})$; $\mathrm{-} \bigcirc$, electrolytic; $\Delta \longrightarrow \Delta$, control. The arrow indicates when, during the sequence of postinjection water tests, saccharin testing was started. 
Table 1

Mean Water Intake (in Milliliters) During 50-Min Periods Following 10-Min Training and Test Periods

\begin{tabular}{|c|c|c|c|c|c|c|c|c|c|}
\hline \multirow[b]{3}{*}{ Group } & \multirow[b]{3}{*}{$\mathrm{n}$} & \multirow{2}{*}{\multicolumn{2}{|c|}{$\begin{array}{c}\text { Preinjection } \\
\text { Trial }\end{array}$}} & \multirow{2}{*}{\multicolumn{2}{|c|}{$\begin{array}{c}\text { Training } \\
\text { Trial }\end{array}$}} & \multicolumn{4}{|c|}{ Postinjection Trials* } \\
\hline & & & & & & \multicolumn{2}{|c|}{ Saccharin } & \multicolumn{2}{|c|}{ Water } \\
\hline & & Mean & SD & Mean & SD & Mean & SD & Mean & SD \\
\hline 5, 7-DHT (4 microg) & 7 & 14.3 & 3.4 & 1.6 & .5 & 15.0 & 2.5 & 9.4 & 5.8 \\
\hline 5, 7-DHT (6 microg) & 7 & 15.3 & 6.8 & 3.9 & 1.7 & 15.7 & 2.6 & 7.2 & 2.4 \\
\hline Electrolytic & 5 & 10.6 & 5.2 & 3.5 & 1.7 & 18.0 & 3.2 & 9.0 & 1.5 \\
\hline Control & 7 & 11.3 & 4.3 & 2.4 & 1.1 & 14.0 & 1.6 & 9.7 & 1.5 \\
\hline
\end{tabular}

*Postinjection 50-min water intake is presented as the average intake following either the four saccharin or the five water presentations.

the effects of pairing a fenfluramine injection with the ingestion of a novel taste cue. No evidence was found to support the idea that fenfluramine-induced taste aversions depend on an intact central serotonergic system. The effects of raphe lesions on fenfluramineinduced aversions were comparable to the effects of similar lesions on $\mathrm{LiCl}$-induced aversions, as previously reported (Lorden \& Margules, 1977).

The fact that the relatively specific 5,7-DHT lesions were as effective as the nonspecific electrolytic lesions suggests that the enhanced suppression of saccharin intake observed in the lesion groups was due to a loss of central 5-HT (Nobin \& Bjorklund, 1978). In previous studies, it was found that using the same lesion techniques employed in this study, no loss of forebrain NE or DA could be detected (Lorden \& Margules, 1977). There is some evidence that 5-HT depletion results in changes in body weight and water intake (Lorens et al., 1971; Saller \& Stricker, 1976). Either of these effects might be expected to influence the outcome of the present study. However, no significant differences in body weight or water intake were found that could account for the depression of intake seen in saccharin consumption.

The results of the experiment presented here do not rule out the possibility that the effectiveness of fenfluramine in the conditioned aversion paradigm is due to its central effects. Fenfluramine is known to have effects on catecholaminergic as well as serotonergic systems. Calderini and others (1975) have shown that fenfluramine can decrease whole

Table 2

Telencephalic 5-HT Levels Following Lesions of the Dorsal and Median Raphe Nuclei

\begin{tabular}{llcl}
\hline \multirow{1}{*}{ Group } & & \multicolumn{2}{c}{ 5-HT } \\
\cline { 3 - 4 } & $\mathrm{n}$ & Mean & SD \\
\hline 5, 7-DHT (4 microg) & 7 & .258 & $.137^{*}$ \\
5, 7-DHT (6 microg) & 7 & .240 & $.091^{*}$ \\
Electrolytic & 5 & .263 & $.062^{*}$ \\
Vehicle & 3 & .441 & $.047^{*}$ \\
Sham & 4 & .557 & .039 \\
\hline
\end{tabular}

Note-Values expressed as micrograms of 5-HT/g fresh weight of brain. $\quad{ }^{*}$ Differs from both vehicle and sham groups $(p<.01)$. ${ }^{* *}$ Differs from sham group $(p<.01)$. brain norepinephrine and increase levels of its metabolites. Similar effects on dopamine neurons have been noted (Fuller, Perry, \& Clemens, 1976; Jori, Dolfini, Tognoni, \& Garattini, 1973). Fenfluramine releases NE, DA, and 5-HT from synaptosomes, but its effects on 5-HT are the most potent (Offermeier \& du Preez, 1978).

Several investigators have now demonstrated that reduction in central 5-HT by electrolytic or 5,7dihydroxytryptamine or 5,7-dihydroxytryptamine lesions or by parachlorophenylalanine treatment does not interfere with fenfluramine-induced anorexia (Hollister et al., 1975; Sugrue et al., 1975). Furthermore, selective reduction of NE, DA, or both catecholamines also fails to block or attenuate the dose-dependent effects of fenfluramine on food intake (Hollister et al., 1975). It is possible that fenfluramine has a direct action on 5-HT receptors or that the anorexic effects and aversion-inducing effects of the drug are mediated by serotonergic systems spared by the types of lesions used in these investigations.

In addition to its central effects, however, fenfluramine is known to have a number of peripheral effects such as the production of hypolipidemia. It has been shown that fenfluramine can directly inhibit the synthesis of glycerolipids (Brindley, Bowley, Sturton, Pritchard, Burditt, \& Cooling, 1978). Furthermore, in humans, an occasional side effect of fenfluramine is gastrointestinal distress (Stunkard, Rickels, \& Hesbacher, 1973). Thus, at the dose used in this study, fenfluramine may act in a manner similar to that proposed for $\mathrm{LiCl}$ to produce taste aversions. It remains to be determined whether an enhancement of taste aversion learning would be observed if an agent such as amphetamine, a drug which appears to act centrally to induce aversions (Roberts \& Fibiger, 1975), were used in serotonin-depleted rats. It is possible that the effect of the raphe lesions is to intensify the gastrointestinal malaise experienced as a result of the drug injections.

\section{REFERENCES}

Berger, B. D. Conditioning of food aversions by injections of psychoactive drugs. Journal of Comparative and Physiological Psychology, 1972, 81, 21-26. 
Brindley, D. N., Bowley, M., Sturton, R. G., Pritchard, P. H., Burditt, S. L., \& Cooling, J. Mode of action of fenfluramine and derivatives and their effects on glycerolipid metabolism. In S. Garattini \& R. Samanin (Eds.), Central mechanisms of anorectic drugs. New York: Raven, 1978.

Calderini, G., Morselli, P. L., \& Garattini, S. Effect of amphetamine and fenfluramine on brain noradrenaline and MOPEG-SO . European Journal of Pharmacology, 1975, 34, 345-350.

Cappell, H., \& LeBlanc, A. E. Conditioned aversion to saccharin by single administrations of mescaline and d-amphetamine. Psychopharmacologia (Berlin), 1971, 22, 352-356.

Cappell, H., LeBlanc, A. E., \& Herling, S. Modification of the punishing effects of psychoactive drugs in rats by previous drug experience. Journal of Comparative and Physiological Psychology, 1975, 89, 347-356.

CAREY, R. J. Effects of selective forebrain depletions of norepinephrine and serotonin on the activity and food intake effects of amphetamine and fenfluramine. Pharmacology, Biochemistry and Behavior, 1976, 5, 519-523.

Clineschmidt, B. V., Totaro, J. A., McGuffin, J. C., \& Pfleuger, A. B. Fenfluramine: Long term reduction in brain serotonin (5-hydroxytryptamine). European Journal of Pharmacology, 1976, 35, 211-214.

Fuller, R. W., Perry, K. W., \& Clemens, J. A. Elevation of 3,4-dihydroxyphenylacetic acid concentration in rat brain and stimulation of prolactin secretion by fenfluramine: Evidence for antagonism at dopamine receptor sites. Journal of Pharmacy and Pharmacology, 1976, 28, 643-644.

Goudie, A. J., \& Thornton, E. W. Effects of drug experience on drug induced conditioned taste aversions: Studies with amphetamine and fenfluramine. Psychopharmacologia (Berlin), $1975,44,77-82$.

HARVEY, J. A., \& Lints, C. E. Lesions in the medial forebrain bundle: Relationship between pain sensitivity and telencephalic content of serotonin. Journal of Comparative and Physiological Psychology, 1971, 74, 28-36.

HARVEY, J. A., \& McMaster, S. E. Fenfluramine: Evidence for a neurotoxic action on midbrain and long-term depletion of serotonin. Psychopharmacology Communications, 1975, 1, 217-228.

Hollister, A. S., Ervin, G. N., Cooper, B. R., \& Breese, G. R. The roles of monoamine neural systems in the anorexia produced by $(+)$ - amphetamine and related compounds. Neuropharmacology, 1975, 14, 715-723.

Jacobowitz, D. M., \& Richardson, J. Method for the rapid determination of norepinephrine, dopamine, and serotonin in the same brain region. Pharmacology, Biochemistry and Behavior, 1978, 8, 515-519.

Jori, A., Dolfini, E., Tognoni, G., \& Garattini, S. Differential effects of amphetamine, fenfluramine and norfenfluramine stereoisomers on the increase of striatum homovanillic acid in rats. Journal of Pharmacy and Pharmacology, 1973, 25, 315-318.

Koe, B. K., \& Weissman, A. p-Chlorophenylalanine: A specific depletor of brain serotonin. Journal of Pharmacology and Experimental Therapeutics, 1966, 154, 499-516.

LORDEN, J. F., \& Margules, D. L. Enhancement of a conditioned taste aversion by lesions of the midbrain raphe nuclei that deplete serotonin. Physiological Psychology, 1977, 5, 273-279.

Lorden, J. F., \& Oltmans, G. A. Alteration of the characteristics of learned taste aversion by manipulation of serotonin levels in the rat. Pharmacology, Biochemistry \& Behavior, 1978, 8, 13-18.
LORENS, S. A. Raphe lesions in cats: Forebrain serotonin and avoidance behavior. Pharmacology, Biochemistry \& Behavior, 1973, 1, 487-490.

Lorens, S. A., Sorenson, J. P., JR., \& Yunger, L. M. Behavioral and neurochemical effects of lesions in the raphe system of the rat. Journal of Comparative and Physiological Psychology, 1971, 77, 48-52.

LoRENS, S. A., \& Yunger, L. M. Morphine analgesia, two-way avoidance, and consummatory behavior following lesions in the midbrain raphe nuclei of the rat. Pharmacology, Biochemistry and Behavior, 1974, 2, 215-221.

NaCHMAN, M. Learned aversion to the taste of lithium chloride and generalization to other salts. Journal of Comparative and Physiological Psychology, 1963, 56, 343-349.

NACHMAN, M. Learned taste and temperature aversions due to lithium chloride sickness after temporal delays. Journal of Comparative and Physiological Psychology, 1970, 73, 22-30.

NaChman, M., \& HaRTley, P. L. Role of illness in producing learned taste aversions in rats: A comparison of several rodenticides. Journal of Comparative and Physiological Psychology, 1975, 89, 1010-1018.

Nobin, A., \& BJoRkiUnd, A. Degenerative effects of various neurotoxic indoleamines on central monoamine neurons. Annals of the New York Academy of Sciences, 1978, 305, 305-327.

Offermeier, J., \& DU PREEz, H. G. Effects of anorectics on uptake and release of monoamines in synaptosomes. In S. Garattini \& R. Samanin (Eds.), Central mechanisms of anorectic drugs. New York: Raven, 1978.

Parker, L., Failor, A., \& Weidman, K. Conditioned preferences in the rat with an unnatural need state: Morphine withdrawal. Journal of Comparative and Physiological Psychology, 1973, 82, 294-300.

Quock, R. M., \& BeAl, G. A. Fenfluramine-induced hyperthermia and stimulation in the rabbit. Research Communication in Chemical Pathology and Pharmacology, 1976, 13, 401-409.

Roberts, D. C. S., \& Fibiger, H. C. Attenuation of amphetamineinduced conditioned taste aversion following intraventricular 6-hydroxydopamine. Neuroscience Letters, 1975, 1, 343-347.

SAller, C., \& STRICKer, E. Hyperphagia and increased growth in rats after intraventricular injections of 5,7-dihydroxytryptamine. Science, 1976, 192, 385-387.

Samanin, R., Ghezzi, D., Valzelli, L., \& Garattini, S. The effects of selective lesioning of brain serotonin or catecholamine containing neurones on the anorectic activity of fenfluramine and amphetamine. European Journal of Pharmacology, 1972, 19, 318-322.

Stunkard, A., Rickels, K., \& Hesbacher, P. Fenfluramine in the treatment of obesity. Lancet, 1973, 1, 503-505.

Srebro, B., \& Lorens, S. A. Behavioral effects of selective midbrain raphe lesions in the rat. Brain Research, 1975, 89, 303-325.

Sugrue, M. F., Goodlet, I., \& McIndewar, I. Failure of depletion of rat brain 5-hydroxytryptamine to alter fenfluramineinduced anorexia. Journal of Pharmacy and Pharmacology, 1975, 27, 950-953.

TENEN, S. S. The effects of p-chlorophenylalanine a serotonin depletor, on avoidance acquisition, pain sensitivity and related behavior in the rat. Psychopharmacologia (Berlin), 1967, 10, 204-219.

Trulson, M. E., \& JAcobs, B. L. Behavioral evidence for the rapid release of CNS serotonin by PCA and fenfluramine. European Journal of Pharmacology, 1976, 36, 149-154.

(Received for publication September 21, 1978; revision accepted November 13, 1978.) 